Louisiana State University

LSU Digital Commons

Faculty Publications

Department of Chemistry

$6-18-2020$

\title{
Controllable and Scalable Engineered Soil Surrogates Utilizing \\ Simulated Soil Organic Matter for the Study of Environmental, Ecological, and Agricultural Processes
}

\author{
Arjun Pandey \\ Louisiana State University \\ Benjamin J. Haywood \\ Louisiana State University \\ Ghada Abdalla \\ Louisiana State University \\ Stephen Smith \\ Louisiana State University \\ Balamurugan Subramanian \\ Louisiana State University
}

See next page for additional authors

Follow this and additional works at: https://digitalcommons.Isu.edu/chemistry_pubs

\section{Recommended Citation}

Pandey, A., Haywood, B., Abdalla, G., Smith, S., Subramanian, B., Spivak, D., \& Cook, R. (2020). Controllable and Scalable Engineered Soil Surrogates Utilizing Simulated Soil Organic Matter for the Study of Environmental, Ecological, and Agricultural Processes. ACS Earth and Space Chemistry, 4 (6), 912-919. https://doi.org/10.1021/acsearthspacechem.0c00091

This Article is brought to you for free and open access by the Department of Chemistry at LSU Digital Commons. It has been accepted for inclusion in Faculty Publications by an authorized administrator of LSU Digital Commons.

For more information, please contact ir@lsu.edu. 


\section{Authors}

Arjun Pandey, Benjamin J. Haywood, Ghada Abdalla, Stephen Smith, Balamurugan Subramanian, David A. Spivak, and Robert L. Cook 


\title{
Controllable and Scalable Engineered Soil Surrogates Utilizing Simulated Soil Organic Matter for the Study of Environmental, Ecological, and Agricultural Processes
}

\author{
Arjun Pandey, ${ }^{\dagger}$ Benjamin J. Haywood, ${ }^{\dagger}$ Ghada Abdalla, Stephen Smith, Balamurugan Subramanian, ${ }^{*}$ \\ David A. Spivak,* and Robert L. Cook*
}

Cite This: ACS Earth Space Chem. 2020, 4, 912-919

Read Online

\section{ACCESS |}

山lll Metrics \& More

回国 Article Recommendations

Supporting Information

ABSTRACT: An entirely new, tunable, and scalable platform (model) approach for the detailed study of important molecular processes that take place in geomacromolecular matrices, such as soils, using block copolymer materials at inorganic interfaces has been developed and applied to gain a molecular-level understanding of environmental pollutant/soil interactions. This approach provides a scalable platform with molecular-level control of the soil organic matter (SOM) chemical composition and structure, allowing one to examine proposed SOM interactions with agricultural chemicals (ACs). Accordingly, a series of engineered soil surrogates (ESSs) utilizing simulated SOM was synthesized, in which multiblock oligomers were tethered to silica

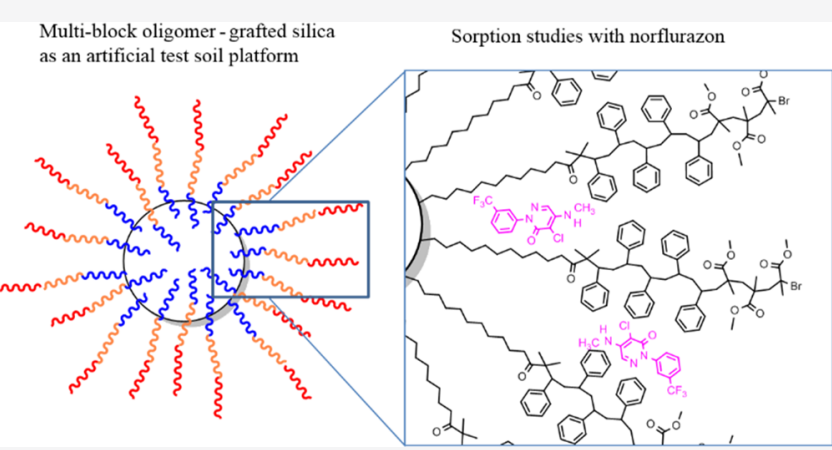
particles, creating one-, two-, and three-tiered ESSs, via controlled radical polymerization. Using norflurazon (NOR) as a model AC sorbate for batch mode sorption experiments, it was found that binding interactions with the ESSs are not just organic contentdriven but are also dependent on the nature of the chemical structure of an ESS. By a stepwise increase in the polarity of the second and third tiers, it is shown that the ability of the ESS to sorb NOR decreases, pointing to a largely hydrophobic driving force for NOR adsorption to the ESSs. The ESS platform approach also allows for the investigation of other, more nuanced interactions with this study, directly showing that hydrogen bonding, electrostatic interactions, conformation, and $\pi$-stacking strongly influence NOR binding. This approach can also be applied to a range of other environmentally and agriculturally important issues, such as soil remediation, microbial community dynamics and evolution, nutrient cycling, and carbon sequestration, where soil variability between replicate samples has limited research advances.

KEYWORDS: sorption, surrogate soil, surface-initiated ATRP (SI-ATRP), norflurazon, soil organic matter (SOM), hydrology

\section{INTRODUCTION}

Despite our reliance on soils to feed the population, with approximately $99 \%$ of consumed food calories coming from terrestrial sources, ${ }^{1}$ and the known negative impacts of agricultural chemicals (ACs) on the environment and human health, a molecular-level understanding of associated soil processes is lacking, primarily because of the complexity and heterogeneity of the natural soil matrix. Also lacking is our molecular-level understanding of a wide range of environmental and agricultural processes. For example, soil remediation, microbial community dynamics and evolution, nutrient cycling, and carbon sequestration studies, especially at the molecular level, have all been hampered because of the variability between the replicate soil samples. Stated differently, because of its complexity and heterogeneity, soil has been a mostly unknown and ill-defined matrix upon which researchers have been studying unknown processes at the molecular level.
Efforts to create "artificial soil test" platforms were first published by the Organization for Economic Cooperation and Development (OECD) $)^{2}$ in 1984, summarized as a combination of $70 \%$ industrial sand (fines in the range 50-200 $\mu \mathrm{m}$ ), $20 \%$ kaolin clay (>30\% kaolinite), and $10 \%$ organic content (sphagnum peat recommended) with $\mathrm{pH}$ close to 5.5-6.0. This or similar recipes have been used in a number of studies; ${ }^{3}$ however, the organic phase remains heterogeneous and illdefined; hence, reproducibility and molecular-level information from these platforms is still elusive. ${ }^{4,5}$ This research aims at the design and synthesis of organically functionalized inorganic

Received: April 8, 2020

Revised: May 13, 2020

Accepted: May 15, 2020

Published: May 15, 2020

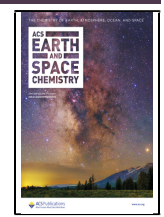


surfaces in order to develop a range of engineered soil surrogates (ESSs) utilizing simulated soil organic matter (SOM) that echo SOM. This model provides a simple, welldefined, and scalable platform to study and understand the effects of soil chemical composition and complexity at the molecular level on processes such as AC sorption.

\section{MATERIALS AND METHODS}

Chemicals. The monomers styrene, 4-vinylphenyl acetate, and methyl methacrylate were obtained from Aldrich and used after passing through an alumina column to remove the inhibitor. The compound 4-vinyl-2-methoxy phenol was obtained from Aldrich and used as a precursor to synthesize the monomer 2-methoxy-4-vinylphenyl acetate.

Trichlorohexylsilane, trichlorododecylsilane, and trichlorooctadecylsilane were obtained from Gelest. Silica gel (Merck grade 9385, pore size 60 ̊, 230-400 mesh, and surface area $\left.550 \mathrm{~m}^{2} / \mathrm{g}\right), 10$-undecen-1-ol, 2-bromoisobutyryl bromide, triethyl amine, trichlorosilane, platinum(0)-1,3divinyl-1,1,3,3-tetramethyldisiloxane complex (Karstedt's catalyst), copper bromide ( $\mathrm{CuBr}), N, N, N^{\prime}, N^{\prime \prime}, N^{\prime \prime}$-pentamethyldiethyltriamine (PMDETA), acetic anhydride, pyridine, dimethylaminopyridine (DMAP), hydrazine hydrate, and dichloromethane (DCM) were obtained from Sigma-Aldrich. Solvents (toluene, diethyl ether, hexane, acetonitrile, ethanol, and ethyl acetate) and ethylenediaminetetraacetic acid (EDTA) disodium salt dihydrate were obtained from VWR. Norflurazon (NOR) was sourced from ChemService.

Synthesis of 10-Undecen-1-yl 2-Bromoisobutyrate (3, Scheme S1). The synthesis of 10-undecen-1-yl-2-bromoisobutyrate was accomplished following a procedure reported previously. ${ }^{6}$ To a solution of 10 -undecen-1-ol (1, Scheme S1) $(4.08 \mathrm{~mL}, 20.36 \mathrm{mmol})$ in $100 \mathrm{~mL}$ of diethyl ether in a $500 \mathrm{~mL}$ round-bottom flask (RBF) was added triethylamine $(3.13 \mathrm{~mL}$, $22.40 \mathrm{mmol}$ ). The flask was cooled to $0{ }^{\circ} \mathrm{C}$, and a solution of 2-bromoisobutyryl bromide (2, Scheme S1) (2.8 mL, 22.4 $\mathrm{mmol})$ in dry diethyl ether $(50 \mathrm{~mL})$ was added dropwise through a dropping funnel under stirring over $10 \mathrm{~min}$. The reaction mixture was allowed to come to room temperature and stirred for $15 \mathrm{~h}$. During the reaction, triethylammonium bromide $\left(\mathrm{Et}_{3} \mathrm{~N}^{+} \mathrm{Br}^{-}\right)$precipitated out from the reaction mixture. After the completion of the reaction, $50 \mathrm{~mL}$ of hexanes was added, and the precipitate was removed by gravity filtration. The solvent was removed under reduced pressure to give a colorless liquid, which was purified by column chromatography using a 25:1 mixture of hexane and ethyl acetate ${ }^{1} \mathrm{H}$ NMR (400 MHz, $\mathrm{CDCl}_{3}$ ): $\delta 5.81$ (ddt, $J=17.2$, $10.1,6.7 \mathrm{~Hz}, 1 \mathrm{H}), 5.02-4.92(\mathrm{~m}, 2 \mathrm{H}), 4.93(\mathrm{t}, J=6.6 \mathrm{~Hz}$, $2 \mathrm{H}), 4.17(\mathrm{t}, J=6.6 \mathrm{~Hz}, 2 \mathrm{H}), 2.90-1.98(\mathrm{~m}, 2 \mathrm{H}) 1.94(\mathrm{~s}, 6 \mathrm{H})$, $1.78-1.61(\mathrm{~m}, 2 \mathrm{H}), 1.56(\mathrm{~s}, 6 \mathrm{H}), 1.44-1.23(\mathrm{~m}, 13 \mathrm{H}) \mathrm{ppm}$.

Synthesis of 11-(2-Bromo-2-methyl)propionyloxy Undecyltrichlorosilane (4, Scheme S1). To a $100 \mathrm{~mL}$ $\mathrm{RBF}$ at $0{ }^{\circ} \mathrm{C}$ were added 10-undecen-1-yl-2-bromoisobutyrate 3 (Scheme S1) (7.11 g, $22.27 \mathrm{mmol}$ ) and trichlorosilane (11.3 $\mathrm{mL}, 112 \mathrm{mmol}$ ) under a nitrogen atmosphere, followed by Karstedt's catalyst $(140 \mu \mathrm{L}, 12 \mu \mathrm{mol})$, and stirred for $24 \mathrm{~h}$. The excess reagent $\left(\mathrm{HSiCl}_{3}\right)$ was evaporated, redissolved in $50 \mathrm{~mL}$ hexanes, and then filtered through a plug of silica to give as a colorless liquid after evaporation. ${ }^{1} \mathrm{H}$ NMR $(400 \mathrm{MHz}$, $\left.\mathrm{CDCl}_{3}\right): \delta 4.17(\mathrm{t}, J=6.6 \mathrm{~Hz}, 2 \mathrm{H}), 1.94(\mathrm{~s}, 6 \mathrm{H}), 1.70-1.60$ $(\mathrm{m}, 4 \mathrm{H}), 1.55-0.89(\mathrm{~m}, 16 \mathrm{H}) \mathrm{ppm}$.

Synthesis of 2-Methoxy-4-vinylphenyl Acetate (6, Scheme S4). Acetic anhydride (63 mL, $666 \mathrm{mmol})$, pyridine
(65 mL, $806 \mathrm{mmol}$ ), and DMAP (0.4 g, $3.27 \mathrm{mmol}$ ) were dissolved in DCM $(50 \mathrm{~mL})$ at $0{ }^{\circ} \mathrm{C}$. Subsequently, 2-methoxy4-vinyl phenol (5, Scheme S4) (10 g, $66.6 \mathrm{mmol})$ in DCM (50 $\mathrm{mL}$ ) was added dropwise, allowed to come to room temperature, and stirred for $24 \mathrm{~h}$. The reaction mixture was washed with $3 \times 100 \mathrm{~mL} 10 \%$ aqueous $\mathrm{CuSO}_{4}$ solution, $3 \times$ $100 \mathrm{~mL}$ saturated aqueous $\mathrm{NaHCO}_{3}$ solution, $3 \times 100 \mathrm{~mL}$ aqueous $\mathrm{NaCl}$ solution, dried over anhydrous $\mathrm{MgSO}_{4}$, and evaporated. Purification by column chromatography using a 1:9 ethyl acetate/hexane mixture yielded a colorless liquid. ${ }^{1} \mathrm{H}$ NMR (400 MHz, $\left.\mathrm{CDCl}_{3}\right): \delta 7.02-6.99(\mathrm{~m}, 3 \mathrm{H}), 6.69(\mathrm{dd}$, $1 \mathrm{H}), 5.70(\mathrm{dd}, 1 \mathrm{H}), 5.26(\mathrm{dd}, 1 \mathrm{H}), 3.87(\mathrm{~s}, 3 \mathrm{H}), 2.32(\mathrm{~s}, 3 \mathrm{H})$ ppm.

Surface Grafting of Tier-1 ESSs on Silica. The $\mathrm{SiO}_{2}$ gel (3.0 g each reaction) was heated overnight at $120{ }^{\circ} \mathrm{C}$. After cooling, toluene $(50 \mathrm{~mL})$ and the trichlorosilyl-end functionalized hydrocarbon $\left(0.216 \mathrm{~mL} \mathrm{C}_{6}, 0.350 \mathrm{~mL} \mathrm{C}_{12}\right.$, or $0.245 \mathrm{~mL}$ $\mathrm{C}_{18}$ ) was added via a syringe dropwise, and the reaction mixture was heated at $80{ }^{\circ} \mathrm{C}$ for $15 \mathrm{~h}$. Afterward, toluene was decanted; the product was washed $(2 \times 25 \mathrm{~mL}$ each $)$ using toluene, acetonitrile, and methanol and dried overnight at 80 ${ }^{\circ} \mathrm{C}$.

Surface Grafting of Tier-1 ESS Coupled with an ATRP Initiator $\left(\mathrm{SiO}_{2}-\mathrm{C}_{11}-\mathrm{Br}\right)$. Silica gel $(6.0 \mathrm{~g})$ was added to 50 $\mathrm{mL}$ of toluene under nitrogen in an oil bath at $80{ }^{\circ} \mathrm{C}$. After 5 min, 11-(2-bromo-2-methyl) propionyloxy undecyltrichlorosilane $(4$, Scheme S1) $(0.45 \mathrm{~mL})$ was added dropwise and refluxed for $18 \mathrm{~h}$, followed by cooling and washing with toluene, acetonitrile, and ethanol $(2 \times 50 \mathrm{~mL}$ solvent each wash). The particles were then dried under nitrogen in an oven at $50{ }^{\circ} \mathrm{C}$ for $48 \mathrm{~h}$.

Surface Graft Extension for the Tier-2 Oligo(styrene) $)_{n}$ Block ESS $\left(\mathrm{SiO}_{2}-\mathrm{C}_{11}-\mathrm{PS}\right)$. To a $500 \mathrm{~mL} \mathrm{RBF}$ charged with $50 \mathrm{~mL}$ of toluene, $5.0 \mathrm{~g}$ of $\mathrm{SiO}_{2}-\mathrm{C}_{11}-\mathrm{Br}$ with $4.37 \%$ total organic fraction (TOF) $\left(0.218 \mathrm{~g} \mathrm{C}_{11}-\mathrm{Br}, 0.68\right.$ $\mathrm{mmol}$ ) was added. After $5 \mathrm{~min}$, while purging with $\mathrm{N}_{2}$, the $\mathrm{Cu}(\mathrm{I}) \mathrm{Br}(212 \mathrm{mg}, 1.48 \mathrm{mmol})$ catalyst, the PMDETA ligand $(0.32 \mathrm{~mL}, 1.53 \mathrm{mmol})$, and the styrene monomer $(3.0 \mathrm{~g}, 28.8$ mmol) were added. The RBF was fitted with a condenser, followed by purging with $\mathrm{N}_{2}$ for $5 \mathrm{~min}$, and then placed in an oil bath at $90{ }^{\circ} \mathrm{C}$ under stirring for $1 \mathrm{~h}$. The reaction was cooled to room temperature, washed with $(2 \times 50 \mathrm{~mL}$ each $)$ toluene, acetonitrile, ethanol, half-saturated aqueous EDTA, water, and ethanol, and then dried at $50{ }^{\circ} \mathrm{C}$ for $48 \mathrm{~h}$, giving a faint blue powder.

Surface Graft Extension for the Tier-2 Oligo-(4acetoxystyrene $)_{n}$ Block ESS $\left(\mathrm{SiO}_{2}-\mathrm{C}_{11}-\mathrm{PAS}\right)$. To a 250 $\mathrm{mL}$ RBF, $17 \mathrm{~mL}$ of xylene and $2.28 \mathrm{~g}$ of $\mathrm{SiO}_{2}-\mathrm{C}_{11}-\mathrm{Br}$ with $4.52 \%$ TOF $\left(0.10 \mathrm{~g}, 0.32 \mathrm{mmol} \mathrm{C}{ }_{11}-\mathrm{Br}\right)$ were added, followed by purging with $\mathrm{N}_{2}$. After $5 \mathrm{~min}$, the $\mathrm{Cu}(\mathrm{I}) \mathrm{Br}(182 \mathrm{mg}, 1.27 \times$ $\left.10^{-3} \mathrm{~mol}\right)$ catalyst, the PMDETA ligand $(0.32 \mathrm{~mL}, 1.53$ $\mathrm{mmol})$, and the monomer 4-acetoxystyrene $(7.8 \mathrm{~g}, 48 \mathrm{mmol})$ were added while purging. The RBF was fitted with a condenser and purged with $\mathrm{N}_{2}$ gas for another $5 \mathrm{~min}$ and then placed in an oil bath at $145{ }^{\circ} \mathrm{C}$ under stirring for $24 \mathrm{~h}$. The resultant mixture was cooled to room temperature; washed with $(2 \times 50 \mathrm{~mL}$ each $)$ toluene, acetonitrile, ethanol, half-saturated aqueous EDTA, water, and ethanol; and then dried in an oven at $50{ }^{\circ} \mathrm{C}$ under $\mathrm{N}_{2}$ for $48 \mathrm{~h}$, giving a tancolored powder.

Surface Graft Extension for the Tier-2 Oligo-(4acetoxy-3-methoxystyrene $)_{n}$ Block ESS $\left(\mathrm{SiO}_{2}-\mathrm{C}_{11}-\right.$ PAMS). To a $250 \mathrm{~mL} \mathrm{RBF}, 17 \mathrm{~mL}$ of xylene and $2.26 \mathrm{~g}$ of 


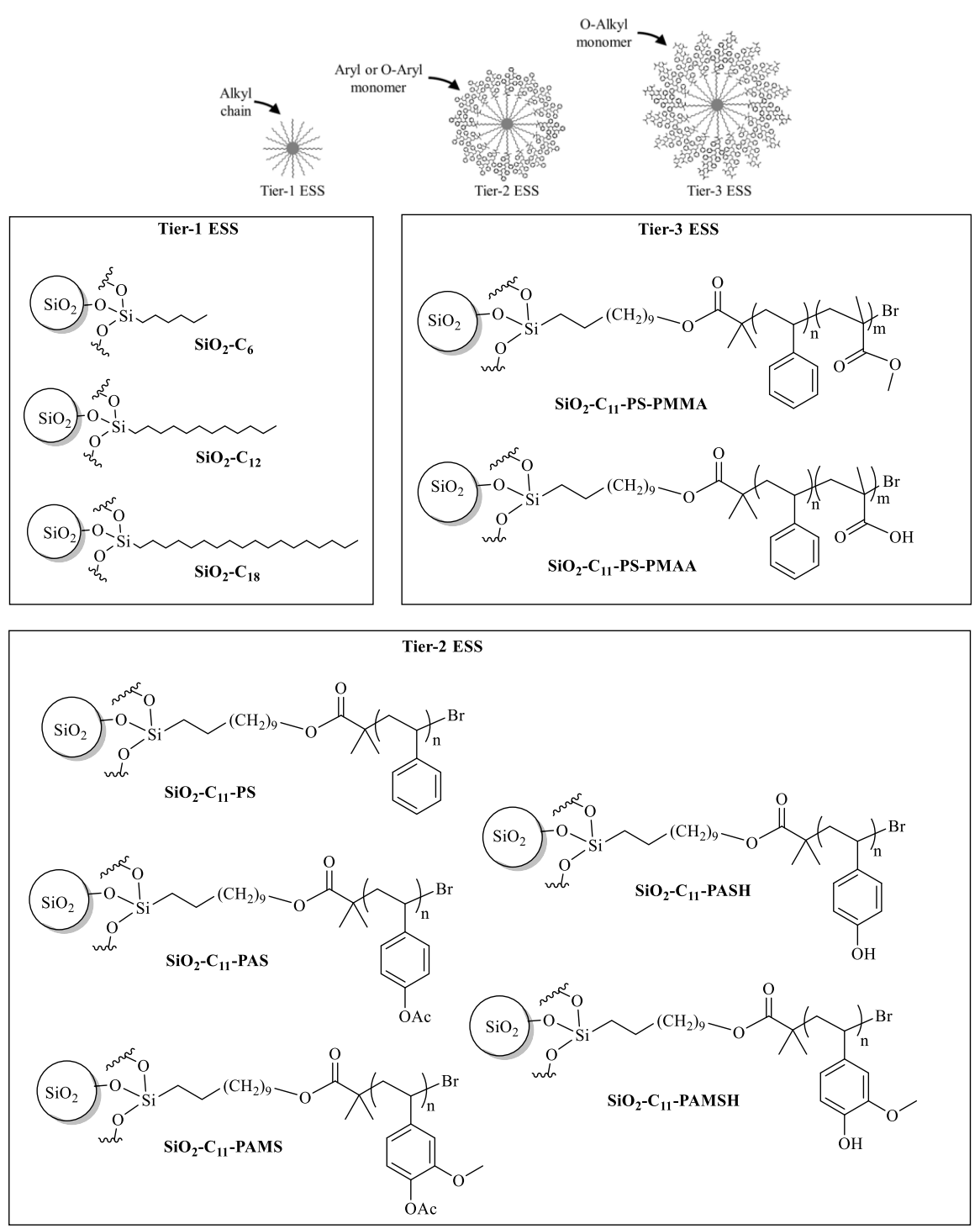

Figure 1. Representative tier-1, tier-2, and tier-3 ESSs.

$\mathrm{SiO}_{2}-\mathrm{C}_{11}-\mathrm{Br}$ with 4.42 \% TOF $\left(0.099 \mathrm{~g}, 0.31 \mathrm{mmol} \mathrm{C}{ }_{11}-\mathrm{Br}\right)$ were added, followed by purging with $\mathrm{N}_{2}$. After $5 \mathrm{~min}$, the $\mathrm{Cu}(\mathrm{I}) \mathrm{Br}$ (184 mg, $1.28 \mathrm{mmol})$ catalyst, the PMDETA ligand (0.32 mL, $1.53 \mathrm{mmol}$ ), and the monomer 2-methoxy-4vinylphenyl acetate $(6$, Scheme S2) (10.0 g, $52 \mathrm{mmol})$ were added while purging. The RBF was fitted with a condenser, purged with $\mathrm{N}_{2}$ gas for another $5 \mathrm{~min}$, and then placed in an oil bath at $145{ }^{\circ} \mathrm{C}$ under stirring for $24 \mathrm{~h}$. The resultant mixture was cooled down to room temperature; washed with $(2 \times 50$ $\mathrm{mL}$ each) toluene, acetonitrile, ethanol, half-saturated aqueous EDTA, water, and ethanol; and then dried in an oven under $\mathrm{N}_{2}$ at $50{ }^{\circ} \mathrm{C}$ for $24 \mathrm{~h}$, giving a tan-colored powder.

Hydrolysis of the Acetoxy Group of $\mathrm{SiO}_{2}-\mathrm{C}_{11}-\mathrm{PAS}$ and $\mathrm{SiO}_{2}-\mathrm{C}_{11}$-PAMS. Approximately, $2.0 \mathrm{~g}$ of polymergrafted silica $\mathrm{SiO}_{2}-\mathrm{C}_{11}-\mathrm{PAS} / \mathrm{SiO}_{2}-\mathrm{C}_{11}-\mathrm{PAMS}$ was added to a $250 \mathrm{~mL} \mathrm{RBF}$, followed by addition of tetrahydrofuran (THF) (40 mL/g of polymer-functionalized silica). While stirring, hydrazine hydrate $(1.165 \mathrm{~mL} / \mathrm{g}$ polymer grafted silica) was added dropwise, the RBF was flushed with $\mathrm{N}_{2}$ gas, and then sealed with a stopper. After stirring at room temperature for 10 $\mathrm{h}$, the resulting mixture was washed with $(2 \times 50 \mathrm{~mL}$ each $)$
THF, ethyl acetate, and ethanol and then oven-dried under $\mathrm{N}_{2}$ at $50{ }^{\circ} \mathrm{C}$ for $48 \mathrm{~h}$, giving a tan-colored powder.

Surface Graft Extension for the Tier-3 Oligo(styrene) $)_{n}$-(methylmethacrylate $)_{m}$ Block ESS $\left(\mathrm{SiO}_{2}-\right.$ $\mathrm{C}_{11}$-PS-PMMA). In a $500 \mathrm{~mL} \mathrm{RBF}, 50 \mathrm{~mL}$ of toluene was added. Subsequently, $5.0 \mathrm{~g}$ of $\mathrm{SiO}_{2}-\mathrm{C}_{11}-\mathrm{Br}$ with $2.87 \% \mathrm{TOF}$ (0.14 g, $0.45 \mathrm{mmol} \mathrm{C}_{11}-\mathrm{Br}$ ) were added, followed by purging with $\mathrm{N}_{2}$. After $5 \mathrm{~min}$, the $\mathrm{Cu}(\mathrm{I}) \mathrm{Br}(212 \mathrm{mg}, 1.48 \mathrm{mmol})$ catalyst, the PMDETA ligand $(0.32 \mathrm{~mL}, 1.53 \mathrm{mmol})$, and the styrene monomer $(2.0 \mathrm{~g}, 19.2 \mathrm{mmol})$ were added while purging. The RBF was fitted with a condenser, purged with $\mathrm{N}_{2}$ gas for another $5 \mathrm{~min}$, and then placed in an oil bath at $90{ }^{\circ} \mathrm{C}$ under stirring for $1 \mathrm{~h}$. After cooling to room temperature, the solvent along with the dissolved unreacted monomer was decanted off under $\mathrm{N}_{2}$, followed by addition of $50 \mathrm{~mL}$ of toluene and purging with $\mathrm{N}_{2}$. After $5 \mathrm{~min}$, the additional $\mathrm{CuBr}$ $(212 \mathrm{mg}, 1.48 \mathrm{mmol})$ catalyst, the PMDETA ligand $(0.32 \mathrm{~mL}$, $1.53 \mathrm{mmol}$ ), and the methyl methacrylate monomer ( $4.0 \mathrm{~g}, 40$ mmol) were added under $\mathrm{N}_{2}$. The $\mathrm{RBF}$ was fitted with a condenser again, and the reaction mixture was purged with $\mathrm{N}_{2}$ for $5 \mathrm{~min}$, followed by refluxing at $90{ }^{\circ} \mathrm{C}$ under stirring for 18 h. Upon cooling to room temperature, the reaction mixture 
Table 1. Calculated Values of TOF (\% TOF), Grafting Density, and Average Degree of Polymerization (DP ${ }_{\text {avg }}$ ) from Which Elemental Percentages and the $\mathrm{O} / \mathrm{C}$ Values Were Derived

\begin{tabular}{|c|c|c|c|c|c|c|c|c|c|c|c|}
\hline & entry & ESS identifier & $\%$ TOF & $\begin{array}{c}\text { grafting density }^{a} \\
\# \mathrm{mmol} / \mathrm{g}\end{array}$ & $\begin{array}{l}\mathrm{DP}_{\text {avg. }} \\
\text { (tier-2) }\end{array}$ & $\begin{array}{l}\mathrm{DP}_{\text {avg. }} \\
(\text { tier-3) }\end{array}$ & $\% \mathrm{C}^{b}$ & $\% \mathrm{H}^{b}$ & $\% \mathrm{O}^{b}$ & $\% \mathrm{Br}^{b}$ & $\mathrm{O} / \mathrm{C}^{b}$ \\
\hline \multirow[t]{4}{*}{ tier-1 } & ESS1 & $\mathrm{SiO}_{2}$ & 2.24 & & & & & & & & \\
\hline & ESS2 & $\mathrm{SiO}_{2}-\mathrm{C}_{6}$ & 2.59 & 0.304 & & & 2.19 & 0.40 & & & \\
\hline & ESS3 & $\mathrm{SiO}_{2}-\mathrm{C}_{12}$ & 4.32 & 0.255 & & & 3.68 & 0.64 & & & \\
\hline & ESS4 & $\mathrm{SiO}_{2}-\mathrm{C}_{18}$ & 4.97 & 0.196 & & & 4.24 & 0.73 & & & \\
\hline \multirow[t]{5}{*}{ tier-2 } & ESS5 & $\mathrm{SiO}_{2}-\mathrm{C}_{11}-\mathrm{PS}$ & 15.30 & 0.137 & 8.9 & & 12.71 & 1.22 & 0.39 & 0.98 & 0.03 \\
\hline & ESS6 & $\mathrm{SiO}_{2}-\mathrm{C}_{11}-\mathrm{PAS}$ & 18.36 & 0.140 & 7.4 & & 12.19 & 1.40 & 3.68 & 1.09 & 0.30 \\
\hline & ESS7 & $\mathrm{SiO}_{2}-\mathrm{C}_{11}-\mathrm{PAMS}$ & 18.50 & 0.137 & 6.5 & & 12.25 & 1.25 & 4.06 & 0.94 & 0.33 \\
\hline & ESS8 & $\mathrm{SiO}_{2}-\mathrm{C}_{11}-\mathrm{PASH}$ & 13.94 & 0.147 & 6.0 & & 10.13 & 1.02 & 1.72 & 1.07 & 0.17 \\
\hline & ESS9 & $\mathrm{SiO}_{2}-\mathrm{C}_{11}-\mathrm{PAMSH}$ & 17.65 & 0.147 & 7.0 & & 12.06 & 1.26 & 3.30 & 1.03 & 0.27 \\
\hline \multirow[t]{2}{*}{ tier-3 } & ESS10 & $\mathrm{SiO}_{2}-\mathrm{C}_{11}-\mathrm{PS}-\mathrm{PMMA}$ & 15.54 & 0.089 & 10.6 & 5.7 & 12.44 & 0.72 & 1.73 & 0.65 & 0.14 \\
\hline & ESS11 & $\mathrm{SiO}_{2}-\mathrm{C}_{11}$-PS-PMAA & 9.50 & 0.089 & $10.6^{c}$ & $5.7^{c}$ & 7.50 & 0.50 & 1.09 & 0.41 & 0.15 \\
\hline
\end{tabular}

${ }^{a}$ Values for the tier- 2 and tier-3 ESSs based on $\mathrm{mmol} / \mathrm{g}$ of the $\mathrm{C}_{11}-\mathrm{Br}$ initiator. ${ }^{b}$ Values are calculated using the $\mathrm{DP}_{\text {avg }}$ for tiers 2 and 3 in the table added to the elemental contribution of tier $1, \mathrm{O} / \mathrm{C}$ ratio yielded by $\% \mathrm{C} / \% \mathrm{O}$. ${ }^{c} \mathrm{Based}$ on $\mathrm{DP}_{\text {avg }}$ of ESS10.

Table 2. Freundlich Adsorption Isotherm Binding Parameter $\left(K_{\mathrm{F}}\right)$, Linear Regression Constant $(N)$, and Linear Fit $\left(R^{2}\right)$ for NOR with Each of the ESSs; Calculated Organic Fraction Normalized Distribution Coefficient $\left(K_{\mathrm{oc}}^{\text {sor }}\right)$ at Selected Sorption Aqueous Equilibrium Concentration $\left(C_{\mathrm{aq}}\right)$ of 1, 8, and $20 \mathrm{ppm}$

\begin{tabular}{|c|c|c|c|c|c|c|c|}
\hline & \multirow[b]{2}{*}{ entry } & \multicolumn{3}{|c|}{ sorption } & \multicolumn{3}{|c|}{$\log K_{\mathrm{oc}}^{\mathrm{sor} b}$} \\
\hline & & $\log K_{\mathrm{F}}^{\text {sor } a}$ & $N^{\text {sor }}$ & $R^{2}$ & $C_{\mathrm{aq}}=1 \mathrm{ppm}$ & $C_{\mathrm{aq}}=8 \mathrm{ppm}$ & $C_{\mathrm{aq}}=20 \mathrm{ppm}$ \\
\hline \multirow[t]{4}{*}{ tier-1 } & ESS1 & $1.185(0.103)^{c}$ & $0.746(0.134)$ & 0.838 & $2.855(2.151)$ & $2.626(1.922)$ & $2.525(1.821)$ \\
\hline & ESS2 & $2.051(0.075)$ & $0.992(0.095)$ & 0.948 & $3.633(2.617)$ & $3.626(2.609)$ & $3.622(2.606)$ \\
\hline & ESS3 & $2.824(0.011)$ & $0.910(0.018)$ & 0.998 & $4.179(2.482)$ & $4.098(2.401)$ & $4.062(2.365)$ \\
\hline & ESS4 & $3.199(0.008)$ & $0.797(0.015)$ & 0.998 & $4.493(2.773)$ & $4.310(2.590)$ & $4.229(2.510)$ \\
\hline \multirow[t]{5}{*}{ tier-2 } & ESS5 & $3.033(0.010)$ & $0.853(0.020)$ & 0.997 & $3.846(2.209)$ & $3.714(2.077)$ & $3.655(2.018)$ \\
\hline & ESS6 & $2.837(0.022)$ & $0.974(0.041)$ & 0.990 & $3.571(2.190)$ & $3.548(2.167)$ & $3.537(2.157)$ \\
\hline & ESS7 & $2.246(0.052)$ & $0.993(0.080)$ & 0.963 & $2.972(1.879)$ & $2.966(1.872)$ & $2.963(1.869)$ \\
\hline & ESS8 & $2.699(0.010)$ & $0.909(0.016)$ & 0.998 & $3.551(1.789)$ & $3.469(1.706)$ & $3.433(1.67)$ \\
\hline & ESS9 & $2.543(0.018)$ & $0.785(0.029)$ & 0.992 & $3.269(1.841)$ & $3.075(1.646)$ & $2.989(1.56)$ \\
\hline \multirow[t]{2}{*}{ tier-3 } & ESS10 & $2.524(0.009)$ & $0.907(0.014)$ & 0.999 & $3.329(1.525)$ & $3.245(1.440)$ & $3.208(1.403)$ \\
\hline & ESS11 & $2.540(0.029)$ & $0.861(0.043)$ & 0.985 & $3.556(2.255)$ & $3.431(2.130)$ & $3.376(2.075)$ \\
\hline
\end{tabular}

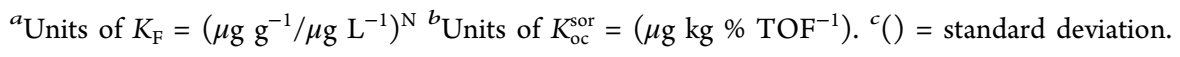

was washed with $(2 \times 50 \mathrm{~mL}$ each $)$ toluene, acetonitrile, ethanol, half-saturated EDTA solution, water, and ethanol and then oven-dried at $50{ }^{\circ} \mathrm{C}$ under $\mathrm{N}_{2}$ for $24 \mathrm{~h}$, giving a bluecolored powder.

Synthesis of $\mathrm{SiO}_{2}-\mathrm{C}_{11}$-PS-PMAA. To a $100 \mathrm{~mL}$ RBF, $0.5 \mathrm{~g}$ of $\mathrm{NaCN}$ and $10 \mathrm{~mL}$ of hexamethylphosphoramide (HMPA) were added and placed in a sonicator for $10 \mathrm{~min}$. After partial dissolution of $\mathrm{NaCN}, 2.0 \mathrm{~g}$ of $\mathrm{SiO}_{2}-\mathrm{C}_{11}-\mathrm{PS}-$ PMMA was added to the RBF and capped. The mixture was placed in an oil bath at $70{ }^{\circ} \mathrm{C}$ and stirred for $24 \mathrm{~h}$, followed by cooling to room temperature and washing with $(2 \times 20 \mathrm{~mL}$ each) toluene, acetonitrile, $0.01 \mathrm{M} \mathrm{HCl}$ solution, and ethanol. The resulting product was oven-dried at $50{ }^{\circ} \mathrm{C}$ under $\mathrm{N}_{2}$ for 24 $\mathrm{h}$, giving a light blue-colored powder.

Washing and Characterization. After synthesis, the ESSs underwent washing with $2 \times 50 \mathrm{~mL}$ each of toluene, acetonitrile, ethanol, half-saturated EDTA solution, water, and finally again with ethanol and oven-dried at $50{ }^{\circ} \mathrm{C}$ for $48 \mathrm{~h}$. The ESSs were then characterized by a combination of thermogravimetric analysis (TGA) with a temperature ramp from room temperature to $600{ }^{\circ} \mathrm{C}$, solid-state nuclear magnetic resonance (NMR) via the ${ }^{1} \mathrm{H}-{ }^{13} \mathrm{C}$ cross-polarization magic angle spinning (CP-MAS) technique, and X-ray photoelectron spectroscopy (XPS) (see Supporting Information SI1 for Experimental Details). Prior to the isotherm experiments, the
ESSs were washed in three repetitions by shaking with $17 \mathrm{~mL}$ of $18 \mathrm{M} \Omega$ high-pressure liquid chromatography-grade water for $24 \mathrm{~h}$, followed by removal of liquid phase and oven-drying at $50{ }^{\circ} \mathrm{C}$ for $24 \mathrm{~h}$.

NOR Sorption and Desorption Isotherms. Batch sorption and desorption isotherm experiments were carried out in accordance with the OECD method 106 [OECD (2000)]..$^{7}$ Each experiment was performed with sets consisting of four replicates for each data point, a background solution (18 $\mathrm{M} \Omega$ water containing $0.01 \mathrm{M} \mathrm{CaCl}_{2}, 100 \mathrm{ppm} \mathrm{NaN}_{3}$, and $0.05 \mathrm{M}$ MES at a $\mathrm{pH}$ of 5.75) with an ESS blank, and a NOR solution control (NOR concentration control). Specifically, the isotherms were performed with eight NOR concentrations of $1,2,4,6,8,12,16$, and $20 \mathrm{ppm}$, with the mixtures horizontally being shaken in the dark at $150 \mathrm{rpm}$ at $25 \pm 1{ }^{\circ} \mathrm{C}$, and then centrifuged at $3400 \mathrm{rpm}$ for $10 \mathrm{~min}$ (more details are provided in Supporting Information SI2).

In accordance with the OECD method 106 (SI1 and SI2), prior to the NOR isotherm experiments with the ESSs, the soil-to-solution ratio and mass balance, as well as sorptiondesorption kinetics equilibrium experiments, were performed to determine the appropriate solution-to-soil ratio and equilibrium time for each ESS studied, with the results being summarized in Table S1. 


\section{RESULTS AND DISCUSSION}

ESS Design and Synthesis. The model soil platform assembly starts from the mineral surface with subsequent addition of alkyl, aryl, and finally polar hydrophilic domains or tiers. The choice of the alkyl inner tier is based on recent studies which show that predominantly alkyl moieties are sorbed to clay surfaces from humic substance solutions (SI3) ${ }^{8,9}$ The choice of aryl moieties as the middle tier and polar hydrophilic moieties in the outer tier (Figure 1) is based on the recent studies of sequential extractions and advanced NMR analyses of isolates and soils. ${ }^{10,11}$ The platform synthesis of tier-1 ESSs (Figure 1) consisted of hydrocarbon aliphatic chains of 6,12 , and 18 carbons immobilized on silica by heating with terminal trichlorosilyl derivatives of each hydrocarbon in toluene. For subsequent growth of the tier-2 oligomer blocks, an ATRP initiator was introduced on the free end of the aliphatic chain to give $\mathrm{SiO}_{2}-\mathrm{C}_{11}-\mathrm{Br}$ (Scheme S1).

The surface coverage of $\mathrm{SiO}_{2}-\mathrm{C}_{11}-\mathrm{Br}$ was verified by TGA, and XPS results confirmed the attachment of the $\mathrm{C}_{11}-\mathrm{Br}$ ATRP initiator on the silica particles, as indicated by the $\mathrm{C} 1 \mathrm{~s}$ peak and a $\mathrm{C} 1 \mathrm{~s} / \mathrm{Si} 2 \mathrm{p}$ ratio of 6.54 for a sample with $12.0 \%$ TOF (Supporting Information, Figure S2). The $\mathrm{C}_{11}-\mathrm{Br}$ loading on $\mathrm{SiO}_{2}$ was controlled by the ratio of 11-(2-bromo2-methyl)propionyloxy undecyltrichlorosilane (4, Scheme $\mathrm{S} 1)$ to silica during the grafting process (Figure $\mathrm{S} 3$ ). $\mathrm{SiO}_{2}-\mathrm{C}_{11}-\mathrm{Br}$ loading of approximately $3-5 \%$ TOF was targeted to maintain the final TOF of the ESSs in the 5-25\% range of typical soil models.

The platform synthesis of tier-2 (Figure 1) entails addition of aromatic monomers, providing progressively more "ligninlike" structure to the aromatic zone in the ESS. As a first lignin surrogate, oligostyrene (ESS5, ESSs are categorized by assigned number in Tables 1 and 2) was appended to the aliphatic chain using ATRP conditions modified from literature methods, ${ }^{12,13}$ which employed the $\mathrm{Cu}(\mathrm{I}) \mathrm{Br}$ catalyst and the PMDETA ligand in toluene at $90{ }^{\circ} \mathrm{C}$ (Scheme S2). Through optimization, it was found that the 2:1 initiator $\left(\mathrm{C}_{11}-\mathrm{Br}\right)$ / $\mathrm{Cu}(\mathrm{I}) \mathrm{Br}-\mathrm{PMDETA}$ ratio was effective in providing the desired oligomeric aromatic block with 5-10 units. The average degree of polymerization $\left(\mathrm{DP}_{\text {avg }}\right)$ was a function of the monomer/initiator ratio (Figure S4), which allowed predictive adjustment of the oligostyrene tier to target $\mathrm{DP}_{\text {avg }}$ in the range of 5-10 units, as shown in Table 1.

More realistic lignin surrogates were envisioned to incorporate a phenolic group; however, the acidic phenol was anticipated not to be compatible with the ATRP conditions. ${ }^{4,15}$ Therefore, 4-acetoxystyrene and 4-acetoxy-3methoxystyrene were used as monomers (the acetoxy group used as the protected phenol), which exhibited lower reactivity, requiring the use of refluxing xylenes to achieve polymerization at $140{ }^{\circ} \mathrm{C}$ to give ESS6 and ESS8, respectively. Monomer 4acetoxystyrene was commercially available, while 4-acetoxy-3methoxystyrene (6, Scheme S4) was synthesized using 2methoxy-4-vinylphenol (5, Scheme S4) and acetic anhydride.

$\mathrm{NaOH}$ hydrolysis of the acetyl-protected phenols in ESS6 and ESS8 resulted in the hydrolysis of the ester linker between aliphatic and polyaryl blocks, thereby removing the oligomer from the silica particle, and the loss of silica. Hydrazine in THF provided for the selective removal of the acetyl group (Scheme S3), giving the desired phenolic oligomers in quantitative yield, as determined by TGA and verified by ${ }^{13} \mathrm{C}$ CP-MAS NMR (SI5).
The platform synthesis of tier-3 ESSs incorporated polar groups, such as methacrylic acid, that cannot be directly polymerized by ATRP. ${ }^{14,15}$ Therefore, a block of oligomethylmethacrylate was added to the oligostyrene end of ESS5, using the same conditions as for the synthesis of second tier, which was subsequently converted to methacrylic acid (ESS11) by hydrolysis. Initial methyl methacrylate ester hydrolysis attempts using $\mathrm{NaOH}$ and subsequently with $\mathrm{LiOH}$ at $60{ }^{\circ} \mathrm{C}$ for $18 \mathrm{~h}$ yielded little cleavage of methacrylate ester and a significant silica hydrolysis. Following the reports of specific deprotection of methyl esters using $\mathrm{NaCN} / \mathrm{HMPA}$ at $70{ }^{\circ} \mathrm{C}$ from the literature, ${ }^{16}$ quantitative conversion of methyl methacrylate to methacrylic acid was accomplished, as determined by ${ }^{13} \mathrm{C}$ CP-MAS NMR. The TGA data obtained on a hydrolyzed material (ESS11) using this process showed a decreased percentage of TOF because of the loss of methyl esters and some other material, possibly hydrolysis of the ester located in between the first and second tiers.

The physical characterization of the ESS compositions posed difficulties because of the solid-phase nature of these materials. Solid-state ${ }^{13} \mathrm{C}$ CP-MAS NMR, a semiquantitative method, provided functional group identification. The NMR spectra of ESSs (SI5) show distinct peaks in aliphatic, aromatic, and carbonyl regions corresponding to the chemical structure of the materials.

The organic content of the ESSs was further characterized by TGA, which provided a quantitative measurement of the percentage of TOF ( $\%$ TOF). This was calculated by subtracting the \% mass of water and volatiles including the trace solvent and then by subtracting the \% TOF of the blank silica (SI7). In brief, for the \%TOF calculation using TGA data, the weight loss below $180{ }^{\circ} \mathrm{C}$ is attributed to the evaporation of water and solvent residues and, above $180{ }^{\circ} \mathrm{C}$, to the loss of the ESS organic fraction. Notably, beyond 600 ${ }^{\circ} \mathrm{C}$, the mass changed imperceptibly within experimental error.

The average degree of polymerization of oligomeric blocks $\left(\mathrm{DP}_{\text {avg }}\right)$ as shown in Table 1 was also calculated from TGA data using a generic equation (SI8, eq SI26). To illustrate the calculation, assume a solid substrate ( such as $\mathrm{SiO}_{2}$ ) with mass $\mathbf{S}$, grafted with an initiator-functionalized (tier-1) block of mass I (g). The initiator end of tier-1 block initiated polymerization to form a block of polymer with mass $\mathbf{P}(\mathrm{g})$. TGA data were collected after grafting of an initiator onto $\mathrm{SiO}_{2}$ (tier-1) and after each polymerization step (tier-2 and further). For a tier-2 ESS, $\mathbf{S}$ denotes the mass of an inorganic surface obtained from a TGA measurement with the masses of the aliphatic and aromatic organic oligomers grafted onto the inorganic surface being $\mathbf{I}$ and $\mathbf{P}$, respectively. The \% TOF of tier- 1 and tier- 2 of an ESS ( $\mathrm{A}$ and $\mathrm{B}$, respectively) can be calculated using eqs 1 and 2, respectively. Using the \% TOF values, we can calculate the average mass of the polymerized block $\mathbf{P}$ per oligomer chain using eq 3 and, subsequently, the $\mathrm{DP}_{\text {avg }}$ of tier-2 using eq 4 (for full derivation for tier-2 and tier-3 ESSs see SI8).

$$
\begin{aligned}
& A=\frac{\mathbf{I}}{\mathbf{I}+\mathbf{S}} \\
& B=\frac{\mathbf{I}+\mathbf{P}}{\mathbf{I}+\mathbf{P}+\mathbf{S}} \\
& \frac{\mathbf{P}}{\# \text { moles of } I}=\frac{(A-B)}{A \times(B-1)} \times \mathrm{MW} \text { of } I
\end{aligned}
$$




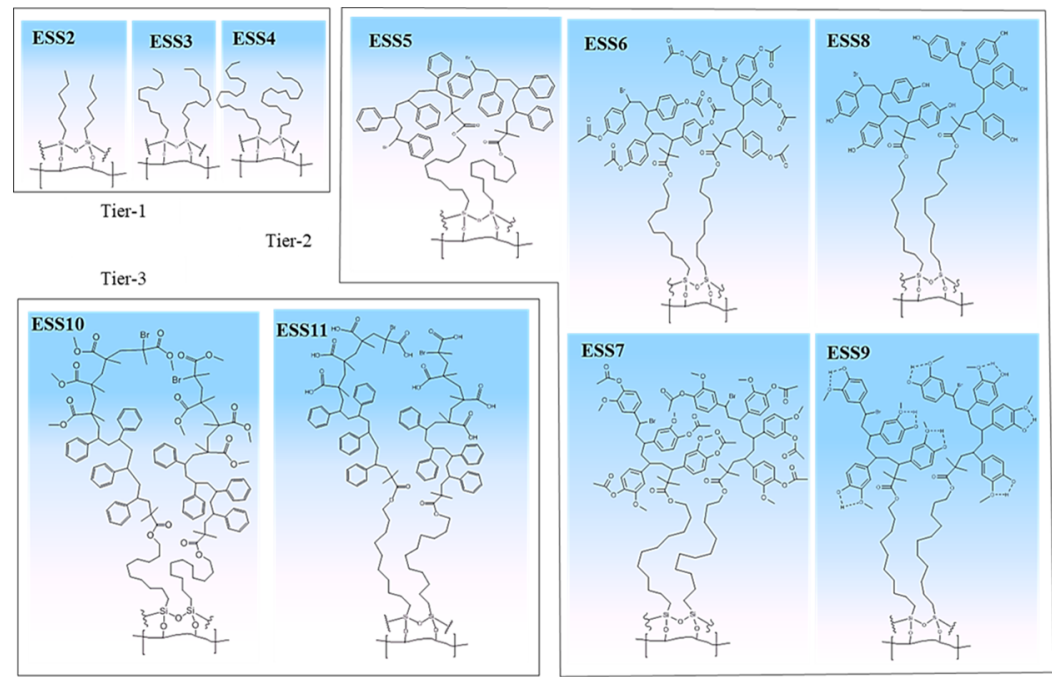

Figure 2. Surface oligomer morphology of ESSs that account for the extent of hydration, oligomer functionality, and intramolecular interactions.

$$
\mathrm{DP}_{\mathrm{avg}}=\frac{\frac{\mathbf{P}}{\# \text { moles of } I}}{\mathrm{MW} \text { of repeating unit }}
$$

Sorption Studies. Once the model soil platforms were synthesized, NOR was employed as a sample AC for the sorption experiments in this study. NOR, classified as a general herbicide for broadleaf plants, was chosen because of its heavy use in agriculture with over $500,000 \mathrm{~kg}$ per year used in the United States alone. ${ }^{17}$ Additionally, NOR has been found to be pervasive in the environment, ${ }^{18,19}$ leading to numerous sorption and desorption studies on soils. ${ }^{2,21}$ Finally, the functional groups in NOR encompass a wide range of possible interactions with SOM that are important to a large number of emergent pollutants including van der Waals, ${ }^{22,23} \pi-\pi$ interactions, ${ }^{20,24}$ and hydrogen bonding (e.g., methyl amino group)..$^{20}$

Isotherms for the binding of NOR to the ESSs were determined using the concentration of NOR present on the ESS sorbent, $C_{\mathrm{s}}\left(\mu \mathrm{g} \mathrm{g}^{-1}\right)$, at sorption equilibrium plotted against the concentration of NOR remaining in the aqueous phase, $C_{\mathrm{aq}}\left(\mu \mathrm{g} \mathrm{L}^{-1}\right)$. The isotherm data were analyzed using two approaches: the distribution coefficient (eq 5) and the Freundlich isotherm (eq 6)

$$
K_{\mathrm{d}}=\frac{C_{\mathrm{s}}}{C_{\mathrm{aq}}}
$$

$$
\log C_{\mathrm{s}}=\log K_{\mathrm{F}}+N \log C_{\mathrm{aq}}
$$

The distribution coefficient, $K_{\mathrm{d}}\left(\mu \mathrm{g} \mathrm{g}^{-1} / \mu \mathrm{g} \mathrm{L}^{-1}\right)$, can be normalized with respect to the organic fraction, $W_{180-600}^{\text {corr }}(\%$ TOF) (eq 7$)$ to give $K_{\mathrm{OC}}\left(\mu \mathrm{g} \mathrm{kg} \% \mathrm{TOF}^{-1}\right)$, which represents the dependence of sorbate binding on the amount of organic fraction found in SOM. ${ }^{20,25}$

$$
K_{\mathrm{oc}}^{\text {sor }}=K_{\mathrm{d}}^{\mathrm{sor}} \cdot \frac{100}{W_{180-600}^{\mathrm{corr}}}
$$

When evaluating the ability of NOR to bind to the different soil surrogates, both $\log K_{\mathrm{oc}}^{\text {sor }}\left(\mu \mathrm{g} \mathrm{kg} \% \mathrm{TOF}^{-1}\right)$ and $\log K_{\mathrm{F}}^{\text {sor }}(\mu \mathrm{g}$ $\left.\mathrm{g}^{-1} / \mu \mathrm{g} \mathrm{L}^{-1}\right)^{\mathrm{N}}$ provide similar trends. For the tier-1 ESSs, there is a systematic increase in $\log K_{\mathrm{oc}}^{\mathrm{sor}}$ and $\log K_{\mathrm{F}}^{\text {sor }}$ (Table 2) that correlates with the increase in $\%$ TOF. This increased sorption capacity, indicated by increased $\log K_{\mathrm{F}}$, is expected as a result of increased favorable hydrophobic-hydrophobic interactions through van der Waals (including London) forces. However, the $\log K_{\mathrm{oc}}^{\text {sor }}$ values, which have been normalized for the organic content, should have remained roughly the same, pointing out that the increase in binding is not just due to increased \% TOF. A possible explanation for this is that for ESS2-ESS4, the longer chains fold over in the aqueous environment to minimize contact with water, and internal sites can form in the interstitial space of the random coil polymer chains. If the polymer is too short to "collapse" or fold, then no interstitial "internal" sites will be formed. Thus, polymer folding can introduce internal and external binding sites, with the internal sites being stronger, by the creation of a more hydrophobic domain with a higher probability of contact with a hydrophobic entity because of two hydrophobic boundaries rather than one and a highly hydrophilic boundary, in this case water, but more sterically hindered (Figure 2). This leads to a less linear NOR sorption behavior with increased chain length, as can be seen by the decreasing $N^{\text {sor }}$ values for ESS2-ESS4 in Table 2. An $N^{\text {sor }}$ value close to 1 indicates homogeneous binding sites that would be seen for a pure partitioning mechanism. An $N^{\text {sor }}$ value tending toward 0 indicates that an increase in binding heterogeneity deviates from a purely partitioning system. $^{25,26}$

The addition of an oligostyrene chain with a $\mathrm{DP}_{\text {avg }}$ of approximately 9 styrene units to the tier- 1 alkyl component gave ESS5. The addition of the tier- 2 oligostyrene increased the \% TOF 3-fold over that of ESS4; however, the $\log K_{\mathrm{F}}^{\text {sor }}$ and $\log K_{\mathrm{oc}}^{\mathrm{sor}}$ of ESS5 did actually exhibit a small decrease. This important finding again corroborates the notion that binding interactions with the surrogate soil are not just a factor of organic content. One explanation for the decrease could be that the interactions between aromatic and alkyl segments decrease the available NOR binding sites on both segments. Another possibility related to the specific chemical structure of tier- 2 could be an increase in the hydration layer in the oligostyrene versus the alkyl segment, which may result in hydrophilic repulsion of NOR by the tier-2 system versus the tier-1 system (Figure 2). This is further supported by the next tier-2 derivative ESS6, which has a slight increase in \%TOF versus ESS5, yet the $\log K_{\mathrm{F}}^{\text {sor }}$ and $\log K_{\mathrm{oc}}^{\text {sor }}$ show more than a 
slight decrease. It is also possible that the acetoxy component of ESS6 sterically blocks access of the hydrophobic NOR binding site to the hydrophobic portion of the surrogate soil. Hydrolysis of the acetoxy group results in a phenolic group to give ESS8, which is capable of hydrogen bonding; however, the phenol at a buffer $\mathrm{pH}$ of 5.75 is still protonated and may only provide a small increase in the polarity of the aromatic region. A small increase in polarity could minimally increase hydration, causing only a small lowering of $\log K_{\mathrm{F}}^{\mathrm{sor}}$ and $\log K_{\mathrm{oc}}^{\mathrm{sor}}$, attesting to the overriding effect of the hydrophobic driving force for NOR binding to the ESSs. This explanation is consistent with the slight lowering of $\log K_{\mathrm{F}}^{\mathrm{sor}}$ and $\log K_{\mathrm{oc}}^{\mathrm{sor}}$ in ESS8 versus ESS6. Binding of NOR to ESS7 decreases with respect to ESS6, most likely in response to the increased polarity, which may again promote hydration of the surrogate soil, thereby repelling NOR. However, when the acetoxy group is hydrolyzed from ESS7 to give ESS9, there is a significant increase in NOR binding. At a sorption $\mathrm{pH}$ of 5.75, the hydrogen bonding in ESS9 (Figure 3) affords electron

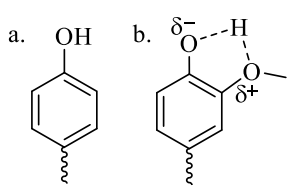

Figure 3. (a) Phenolic group of ESS8 remains neutral at $\mathrm{pH}=5.75$. (b) Role of the presence of a methoxy group in hydrogen bonding that creates a dipole capable of hydration.

donation into the aromatic ring, which promotes $\pi-\pi$ interactions with the electron-deficient aromatic ring of NOR. The partially ionized aromatic ring of ESS9 is also capable of electrostatic interactions with amine groups of NOR. The greater polarity of the ESS9 would also be anticipated to increase hydration, which has a repelling effect on NOR; however, this effect appears to be overcome by the $\pi$ stacking and electrostatic interactions between NOR and ESS9, as described above. The $N^{\text {sor }}$ values show that sorption nonlinearity is aided by binding sites within the polar part of the oligomer chains capable of noncovalent interactions with NOR described above.

Compared to the oligostyrene-functionalized ESS5, both ESS10 and ESS11 tier-3 ESSs exhibit a significant reduction of $\log K_{\mathrm{F}}^{\text {sor }}$ and $\log K_{\mathrm{oc}}^{\text {sor }}$ for NOR, which is consistent with the earlier hypothesis that polar groups create a hydration shell that inhibits the affinity toward and binding of NOR. This important observation supports the idea that interactions of NOR are directed toward the hydrophobic oligostyrene and aliphatic tiers. Hydrolysis of ESS10 to give carboxylic acids in tier-3 (ESS11) does not show a significant change in $\log K_{\mathrm{F}}^{\text {sor }}$, and only a small increase in $\log K_{\mathrm{oc}}^{\text {sor }}$, indicating that the tier- 3 chain only provides a hydration shell and is not participating directly in the binding of NOR. Overall, for the ESS5 through ESS11 (with the exception of ESS9) series, the lower log $K_{\mathrm{F}}^{\text {sor }}$ and $\log K_{\mathrm{oc}}^{\text {sor }}$ can be explained by the hydration process causing elongation of the polymer, thereby eliminating a portion of interstitial (nonlinear) sorption sites. With these nonlinear sites eliminated, more linear adsorption isotherms are formed, and one will obtain higher $N^{\text {sor }}$ values. Altogether, the binding analysis suggests that a combination of oligomer conformation, hydration, and noncovalent interactions plays a role in NOR sorption in soils. The lack of correlation between the O/C ratios from Table 1 and the binding trends from Table 2 clearly demonstrates the need for a more detailed understanding of how chemical structure impacts binding behavior, as afforded by the ESS platform approach utilizing appropriate ESS systems.

The ESS systems presented in this work focus on the organic matter component of a soil and, in doing so, eliminate the potential interference from other real soil components such as clays, metal oxides, carbonates, and sulfates, not to mention microbes. However, this platform also allows systematic incorporation of these additional components in a controlled manner to further extend the scope of the current study. This collection of ESS systems-and the ESS platform conceptwas not conceived to address the full heterogeneity and complexity of soils or to model all the intricate and nuanced interactions that can take place in a real soil. Instead, the ESS platform should be considered as a surrogate designed to address the feasibility of interactions proposed to take place between organic pollutants, including pesticides, and organic matter within soils. This work illustrates that this new platform approach to soils allows one to directly probe proposed molecular interactions that have been challenging to study in otherwise ill-defined natural geomatrices. In particular, ESSs offer a promising tool to elucidate how pollutants interact with soils and can provide new insights into such interactions and proposed mechanisms based on such interactions. Furthermore, this work also shows the potential utility of the ESS platform approach, with appropriately formulated ESSs, in the investigations of the soil microbial community dynamics and evolution, nutrient cycling, and water cycling, advancing our molecular-level mechanistic understanding of a wide range of essential soil processes.

\section{ASSOCIATED CONTENT}

\section{Supporting Information}

The Supporting Information is available free of charge at https://pubs.acs.org/doi/10.1021/acsearthspacechem.0c00091.

Material and methods, soil-to-solution ratio and sorption kinetic experiments, ESS design, ESS synthesis approach, data in the form of NMR spectra and TGA thermograms, and calculations for \% TOF and DP from TGA data (PDF)

\section{AUTHOR INFORMATION}

\section{Corresponding Authors}

Balamurugan Subramanian - Department of Chemistry, Louisiana State University, Baton Rouge, Louisiana 70803, United States; Email: balaunm@yahoo.com

David A. Spivak - Department of Chemistry, Louisiana State University, Baton Rouge, Louisiana 70803, United States; Email: dspivak@lsu.edu

Robert L. Cook - Department of Chemistry, Louisiana State University, Baton Rouge, Louisiana 70803, United States; ○ orcid.org/0000-0003-4246-2951; Email: rlcook@lsu.edu

\section{Authors}

Arjun Pandey - Department of Chemistry, Louisiana State University, Baton Rouge, Louisiana 70803, United States

Benjamin J. Haywood - Department of Chemistry, Louisiana State University, Baton Rouge, Louisiana 70803, United States

Ghada Abdalla - Department of Chemistry, Louisiana State University, Baton Rouge, Louisiana 70803, United States 
Stephen Smith - Department of Chemistry, Louisiana State University, Baton Rouge, Louisiana 70803, United States

Complete contact information is available at:

https://pubs.acs.org/10.1021/acsearthspacechem.0c00091

\section{Author Contributions}

${ }^{\dagger}$ A.P. and B.J.H. contributed equally to this work.

Notes

The authors declare no competing financial interest.

\section{ACKNOWLEDGMENTS}

We gratefully acknowledge funding from the National Science Foundation, Grant CHE-1411547. We would like to thank Dr. Thomas Weldeghiroghis for assistance with solid-state NMR and Dr. Rafael Cueto for assistance with TGA.

\section{REFERENCES}

(1) Pimentel, D.; Greiner, A. Environmental and socio-economic costs of pesticide use. Techniques for Reducing Pesticide Use: Economic and Environmental Benefits; John Wiley and Sons: New York, 1997; Chapter 4.

(2) OECD. OECD Guideline for Testing of Chemicals No. 207: Earthworm, Acute Toxicity Test, 1984.

(3) Hofman, J.; Hovorková, I.; Semple, K. T. The variability of standard artificial soils: Behaviour, extractability and bioavailability of organic pollutants. J. Hazard. Mater. 2014, 264, 514-520.

(4) Cook, R. L. Coupling NMR to NOM. Anal. Bioanal. Chem. 2004, 378, 1484-1503.

(5) Xing, B.; Pignatello, J. J.; Gigliotti, B. Competitive sorption between atrazine and other organic compounds in soils and model sorbents. Environ. Sci. Technol. 1996, 30, 2432-2440.

(6) Yan, J.; Pan, X.; Wang, Z.; Zhang, J.; Matyjaszewski, K. Influence of Spacers in Tetherable Initiators on Surface-Initiated Atom Transfer Radical Polymerization (SI-ATRP). Macromolecules 2016, 49, 92839286.

(7) OECD. OECD Guideline for the Testing of Chemicals No. 106: Adsorption-Desorption Using a Batch Equilibrium Method, 2000.

(8) Wang, K.; Xing, B. Structural and sorption characteristics of adsorbed humic acid on clay minerals. J. Environ. Qual. 2005, 34, 342-349.

(9) Feng, X.; Simpson, A. J.; Simpson, M. J. Chemical and mineralogical controls on humic acid sorption to clay mineral surfaces. Org. Geochem. 2005, 36, 1553-1566.

(10) Kang, S.; Xing, B. Phenanthrene sorption to sequentially extracted soil humic acids and humins. Environ. Sci. Technol. 2005, 39, 134-140.

(11) Lattao, C.; Birdwell, J.; Wang, J. J.; Cook, R. L. Studying organic matter molecular assemblage within a whole organic soil by nuclear magnetic resonance. J. Environ. Qual. 2008, 37, 1501-1509.

(12) Kruk, M.; Dufour, B.; Celer, E. B.; Kowalewski, T.; Jaroniec, M.; Matyjaszewski, K. Grafting Monodisperse Polymer Chains from Concave Surfaces of Ordered Mesoporous Silicas. Macromolecules 2008, 41, 8584-8591.

(13) Save, M.; Granvorka, G.; Bernard, J.; Charleux, B.; Boissière, C.; Grosso, D.; Sanchez, C. Atom Transfer Radical Polymerization of Styrene and Methyl Methacrylate from Mesoporous Ordered Silica Particles. Macromol. Rapid Commun. 2006, 27, 393-398.

(14) Fantin, M.; Isse, A. A.; Gennaro, A.; Matyjaszewski, K. Understanding the Fundamentals of Aqueous ATRP and Defining Conditions for Better Control. Macromolecules 2015, 48, 6862-6875.

(15) Matyjaszewski, K.; Shipp, D. A.; Wang, J.-L.; Grimaud, T.; Patten, T. E. Utilizing Halide Exchange To Improve Control of Atom Transfer Radical Polymerization. Macromolecules 1998, 31, 68366840.

(16) Müller, P.; Siegfried, B. SN2 Reactions with Carboxylic Esters. Selective cleavage of methyl esters. Helv. Chim. Acta 1974, 57, 987994.
(17) Key, B. D.; Howell, R. D.; Criddle, C. S. Fluorinated organics in the biosphere. Environ. Sci. Technol. 1997, 31, 2445-2454.

(18) Gilliom, R. J.; Barbash, J. E.; Crawford, C. G.; Hamilton, P. A.; Martin, J. D.; Nakagaki, N.; Nowell, L. H.; Scott, J. C.; Stackelberg, P. E.; Thelin, G. P.. Pesticides in the Nation's Streams and Ground Water, 1992-2001; US Geological Survey, 2006.

(19) Strynar, M.; Dec, J.; Benesi, A.; Jones, A. D.; Fry, R. A.; Bollag, J.-M. Using19F NMR Spectroscopy to Determine Trifluralin Binding to Soil. Environ. Sci. Technol. 2004, 38, 6645-6655.

(20) Sun, K.; Gao, B.; Ro, K. S.; Novak, J. M.; Wang, Z.; Herbert, S.; Xing, B. Assessment of herbicide sorption by biochars and organic matter associated with soil and sediment. Environ. Pollut. 2012, 163, $167-173$.

(21) Morillo, E.; Maqueda, C.; Reinoso, R.; Undabeytia, T. Effect of two organic amendments on norflurazon retention and release by soils of different characteristics. Environ. Sci. Technol. 2002, 36, 43194325.

(22) Sun, K.; Keiluweit, M.; Kleber, M.; Pan, Z.; Xing, B. Sorption of fluorinated herbicides to plant biomass-derived biochars as a function of molecular structure. Bioresour. Technol. 2011, 102, 9897-9903.

(23) Sheng, G.; Yang, Y.; Huang, M.; Yang, K. Influence of pH on pesticide sorption by soil containing wheat residue-derived char. Environ. Pollut. 2005, 134, 457-463.

(24) Keiluweit, M.; Kleber, M. Molecular-Level Interactions in Soils and Sediments: The Role of Aromatic $\pi$-Systems. Environ. Sci. Technol. 2009, 43, 3421-3429.

(25) Pignatello, J. J.; Xing, B. Mechanisms of slow sorption of organic chemicals to natural particles. Environ. Sci. Technol. 1996, 30, $1-11$.

(26) Wauchope, R. D.; Yeh, S.; Linders, J. B. H. J.; Kloskowski, R.; Tanaka, K.; Rubin, B.; Katayama, A.; Kördel, W.; Gerstl, Z.; Lane, M.; Unsworth, J. B. Pesticide soil sorption parameters: theory, measurement, uses, limitations and reliability. Pest. Manag. Sci. 2002, 58, 419445 . 